\title{
Patent filing strategies for pharmaceuticals in Europe
}

\begin{abstract}
"Owing to the early filing and the lengthy process up to marketing approval, the effective time period in which a patent is of commercial relevance is a lot shorter than the 20-year patent term.
\end{abstract}

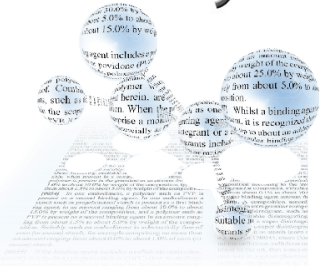

Keywords: clinical data $\bullet$ divisional application $\bullet$ Europe $\bullet$ patent filing strategies

- sufficiency of disclosure

Finding a novel pharmaceutical compound is difficult since most researched drug candidates fail to lead to a marketable product. Furthermore, general increases in the time from the filing of a Clinical Trial Authorization application to an application dossier for marketing authorization tend to significantly drive up total expenses in drug development. In spite of the significant costs involved, marketing approval is not assured at the end.

Accordingly, the few successful drugs that can be marketed must recover all expenses. Cost estimates that take into consideration that profits from drugs that are approved must also pay for clinical trials of drugs that were not approved range from approximately US $\$ 500$ million to nearly US $\$ 2$ billion per approved drug [1].

Because the cost of innovation is high and the cost of imitation is low, the effective protection and enforcement of its intellectual property is of pivotal importance for any research-based pharmaceutical or biotechnology company in order to secure continued growth and long-term success.

One central question, therefore, is how patent protection can be maximized in the pharmaceutical sector. With this question in mind, the present article has its focus on strategic patent filing. More specifically, frequently used patent filing options will be discussed for Europe. Europe, ranking second in 2013 with $27.4 \%$ of world pharmaceutical sales [2], is a key market and for the industry therefore also a main target when seeking intellectual property exclusivity.
This article will focus on two main objectives. First, general concepts for filing patent applications will be discussed. Thereafter, a filing strategy will be mentioned that is useful particularly when contentious proceedings are ongoing and that has recently become again more accessible.

Selection criteria for geographic coverage, possibilities under the Unified Patent Court Agreement and the role of other intellectual property besides patent protection have been left outside the scope of this paper. However, additional information including news related to the Unified Patent Court is available [3].

\section{General filing considerations}

The European Patent Office (EPO) grants patents for a patentable invention. Inter alia, the European Patent Convention (EPC) requires that a patentable invention is novel (Art. 54 EPC), inventive (Art. 56) and sufficiently disclosed (Art. 83 EPC).

Pursuant to Art. 63(1) EPC the term of protection of the European patent is 20 years as from the date of filing of the application. Considering the lengthy process required for obtaining marketing approval, it must be carefully assessed when a patent application should be filed and which invention should be protected in order to be able to maximize patent protection.

As the state of the art grows quickly in successful product areas and since possible earlier patent filings by the competitor should be avoided, the first patent applications for a given compound in the pharmaceutical sector are typically filed rather early in the $R \& D$ process.

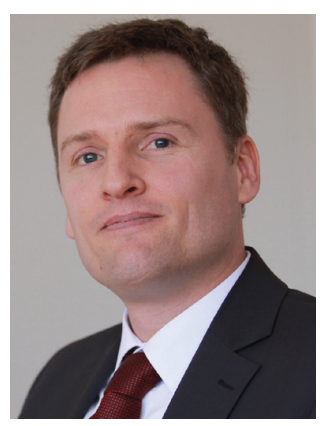

Sebastian Höpfner Bird \& Bird LLP, Maximiliansplatz 22, 80333 Munich, Germany Tel.: +49 893581 6223; +498935816000 Fax: +49 8935816011 sebastian.hoepfner@twobirds.com 
Owing to the early filing and the lengthy process up to marketing approval, the effective time period in which a patent is of commercial relevance is a lot shorter than the 20 -year patent term. To give a patentee more time to recover development costs, he can apply for a supplementary protection certificate that could at best provide for an additional 5 (Regulation [EC] No. 469/2009 of the European Parliament and of the Council of 6 May 2009) or even an additional 5.5 years of protection (Regulation [EC] No 1901/2006 of 12 December 2006).

In addition, a patentee might think of covering different inventive aspects of a product that arise during the product development in different sequentially filed patent applications. Pursuant to Rule 43(2), the EPC provides different patent claim categories including to a product, a process, an apparatus or a use. Thus, similar to a multiple course dinner with a respective wine accompaniment for each course, an originator company can sequentially file patent applications to accompany the different $R \& D$ process stages.

For example, the following individual patent applications could be filed sequentially (not necessarily in this order) with claims directed at:

- Lead compound/its chemical intermediate(s);

- Optimized method of making the lead compound or its chemical intermediate(s);

- Specific polymorphs/derivatives of the lead compound;

- Specific formulation/packaging of the lead compound;

- First and further medical use of the lead compound;

- Screening methods involving the lead compound;

- Combination preparation comprising the lead compound;

- Dosing and treatment regimen involving the lead compound.

Patents on dosage and treatment regimens have become more and more important in the past years. In this context, it is noted that a generics company can typically not deviate much from the originally approved dosing and formulation of the lead compound if it wants to use the originator's compound as 'reference medicine' for their own marketing authorization process. Thus, if a patent covers the actually used dosage regimen a generics company cannot easily design around this scheme.
Concerning the protection of drug polymorphs it should be noted that the examination process before the EPO has become rather strict also in view of decision T 777/08 of the Boards of Appeal of the EPO. In this decision, the board held that at least in the absence of any technical prejudice, the mere provision of a crystalline form of a known pharmaceutically active compound cannot be regarded as involving an inventive step. In other words, it may be necessary to show such prejudice in the prior art in conjunction with an unexpected pharmaceutical activity of the claimed polymorph form to corroborate the argument for an inventive step. This illustrates that the actual filing strategy has to be adapted to each specific case.

During a product's life cycle and development, the most suitable time point should be chosen for filing respective patent applications. The right timing will primarily depend on the specific product that is being developed. Generally, one could consider filing broader claims early during the discovery phase. Later, near product launch, patent applications can be filed covering for example the specific product and formulation. Post-launch, further applications could be filed directed at, for example, combination treatments, novel uses of the compound and novel dosing and/or treatment regimen.

Patent applications will typically be filed as soon as all features that are essential for carrying out the invention are known to the inventor and can be described in sufficient detail to render it apparent to the skilled person how to put the invention into practice. For this one example could already be enough to establish sufficient disclosure in the sense of Art. 83 EPC (see e.g., T617/07, point 46 of the reasons). However, also decision T 491/08 should also be kept in mind in which the board held that the patent application must provide at least some information "in the form of, for example, experimental tests, to the effect that the claimed compound, administered as stated in the claims, has a direct effect on a metabolic mechanism specifically involved in the disease, this mechanism being either known from the prior art or demonstrated in the application per se." If the aforementioned data are available in the application, then supplementary post-published evidence may be taken into account. It is noted, however, that in non-EPO jurisdictions a stricter approach may apply. Furthermore, also before the EPO, post-published data can generally not be used as the sole basis to establish sufficiency (see also decision T 1329/04).

Concerning the treatment regimen, it is notable that in at least one decision (T 108/09) the board held that, depending on the case, clinical data might not necessarily be required for the showing of an enabling disclosure of a treatment regimen. 
The above-outlined approach can help the innovator to optimize the time of protection since each patent will have a different filing and expiry date.

Of course, generics companies may also file patent applications to protect inventive improvements. They can be directed, for example, at a novel work-around that has been identified to avoid third-party rights, but which successfully reproduces the desired therapeutic effect. The publication of such patent applications generates prior art that may become patent hindering for a competitor firm and, if ultimately granted, such patents can also prove to be useful to generate revenue through licensing or to prevent other generics companies from using the claimed work-around technology.

\section{Filing considerations during ongoing contentious proceedings}

During opposition proceedings before the EPO a scenario may occur, where the opposed patent was granted with a limiting amendment to the claims that was later shown to be inadmissible as it represents added matter (Art. 123(2) EPC). If no further amendment is available that can be used without broadening the scope of protection and which removes the objected feature, patentee will fall into an 'inescapable trap', resulting in the revocation of the opposed patent.

In such an event and similar situations, it can prove tremendously helpful for the patentee if at least one divisional patent application is still pending that could form the basis for a new and valid patent.

\section{References}

1 Adams CP, Brantner VV. Estimating the cost of new drug development: is it really 802 million dollars? Health Aff. (Millwood) 25(2), 420-428 (2006).
In this context, it is noted that on April 1, 2014, a decision of the Administrative Council of the EPO entered into force, removing the previous 24-month time limit for the filing of divisional applications (Decision of the Administrative Council of 16 October 2013 [CA/D 15/13]). As a consequence, the filing of divisional applications is again made easier and is possible as long as the earlier (parent) application is pending.

Thus, in particular, if it is expected that a patent is likely to be opposed by a third party, the patentee should consider filing a divisional application as long as the patent application is still pending (i.e., prior to grant), to maintain a valuable strategic flexibility. Additionally, a patent portfolio with patent families that include pending applications will generally be more attractive to potential investors, licensees and buyers.

\section{Acknowledgements}

The author thanks M Alt for reviewing the Editorial.

\section{Financial \& competing interests disclosure}

The author has no relevant affiliations or financial involvement with any organization or entity with a financial interest in or financial conflict with the subject matter or materials discussed in the manuscript. This includes employment, consultancies, honoraria, stock ownership or options, expert testimony, grants or patents received or pending, or royalties.

No writing assistance was utilized in the production of this manuscript.

2 A. The pharmaceutical industry in figures (2014). www.efpia.eu/uploads/Figures_2014_Final.pdf

3 Bird \& Bird. The Unified Patent Court. www.twobirds.com/ 